\title{
Androgenetic Alopecia in a Patient with Klinefelter Syndrome: Case Report and Literature Review
}

\author{
Waleed Alsalhi ${ }^{a}$ Antonella Tosti ${ }^{b}$ \\ aDepartment of Dermatology, College of Medicine, Majmaah University, Al-Majmaah, Saudi Arabia; \\ ${ }^{b}$ Dr. Phillip Frost Department of Dermatology and Cutaneous Surgery, University of Miami Miller School of \\ Medicine, Miami, FL, USA
}

\section{Established Facts}

- Klinefelter syndrome presents clinically with signs of androgen deficiency including low testosterone.

- Androgenetic alopecia develops as a response of the hair follicle cells to androgens in individuals with genetic predisposition.

\section{Novel Insights}

- Patients with Klinefelter syndrome can develop androgenetic alopecia.

- Finasteride is a good treatment option for these patients who might also benefit from the increase level of serum testosterone during finasteride treatment.

\section{Keywords}

Klinefelter syndrome · Alopecia · Hair loss - Testosterone ·

Finasteride

\begin{abstract}
Introduction: Klinefelter syndrome (KS) is defined as (a chromosomal disorder in which males have an extra $\mathrm{X}$ chromosome). KS presents clinically with signs of androgen deficiency including low testosterone. Androgenetic alopecia (AGA) develops as a response of the hair follicle cells to androgens in individuals with genetic predisposition. Case Presentation: We describe a 17-year-old male patient with KS who
\end{abstract}

karger@karger.com www.karger.com/sad

(C) 2020 S. Karger AG, Basel

Karger developed AGA with a Ludwig pattern. Conclusion: Our patient had a good response to oral minoxidil, finasteride, and low-level light therapy.

(c) 2020 S. Karger AG, Basel

\section{Introduction}

Klinefelter syndrome (KS) is a chromosomal disorder affecting males characterized by an extra X chromosome producing the karyotype $47, \mathrm{XXY}$. The extra X chromosome results from either meiotic nondisjunction, where a chromosome fails to separate during the first or second 
Table 1. Summary of reported cutaneous findings in KS [1, 12-15, 22-31]

\begin{tabular}{ll}
\hline Syndromic & Note \\
\hline Gynecomastia [1] & Common (up to 38\%) [22] \\
Incontinentia pigmenti [12-14] & Reported \\
Focal dermal hypoplasia (Goltz syndrome) [15] & Reported \\
Neurofibromatosis type 1 [23] & Reported \\
Sjogren syndrome [24] & Increase incidence \\
Leg ulcer [25-27] & High risk \\
Lupus erythematosus [28] & SLE less severe than in normal men \\
Systemic sclerosis [29] & Association with progressive systemic sclerosis \\
Varicose veins [30] & Frequently associated \\
Paget's disease [31] & Increase incidence \\
\hline
\end{tabular}

KS, Klinefelter syndrome.

division of gametogenesis, or from mitotic nondisjunction in the developing zygote [1]. KS negatively affects testicular growth causing low production of testosterone. KS patients show manifestations of androgen deficiency, including reduced body and facial hair, reduced muscle mass, and enlarged breast tissue [2].

Androgenetic alopecia (AGA) is traditionally considered an androgen-mediated disorders, due to the effects of the potent testosterone derivative dihydrotestosterone (DHT) on genetically predisposed hair follicles. In AGA, terminal hairs gradually miniaturize and convert into vellus-like hairs.

\section{Case Presentation}

A 17-year-old male with KS presented to our clinic with an 18-month history of progressive hair loss. Clinical examination revealed AGA with a female pattern (Stage: Ludwig type II). Trichoscopy showed $20 \%$ hair shaft variability, supporting the diagnosis of AGA. The patient's testosterone level was within normal limits at $609 \mathrm{ng} / \mathrm{dL}$ (normal 300-1,000 ng/dL). He was not taking medications including testosterone replacement. The patients have been started on oral minoxidil $0.625 \mathrm{mg}$ daily, finasteride $1 \mathrm{mg}$ daily, and low-level light therapy (Capillus Pro ${ }^{\mathrm{TM}}, 650 \mathrm{~nm}$ diode laser). Follow-up at 6 months showed excellent clinical improvement with increased hair density.

\section{Discussion/Conclusion}

Scalp, face, axillary, and pubic hair growth are androgen dependent. The role of androgen in male pattern hair loss was established by the anatomist James Hamilton. Hamilton reported that castrated males did not develop premature alopecia or common baldness, unless treated with testosterone [3].

Testosterone is the main circulating androgen. The tissue effects of testosterone are mediated by binding of testosterone to the intracellular androgen receptor [4]. Male patients with androgen insensitivity syndrome caused by a mutation in the androgen receptor gene do not develop baldness. It is, therefore, implied that the binding of testosterone to the androgen receptor is the cause of AGA in men [5]. Role of androgens, on the other hand, is not so well established in women, who often have normal androgen levels. In addition, AGA can occur in females with androgen insensitivity syndrome [6,7].

KS was first described by Dr. Klinefelter et al. [1]. It is the most common human sex chromosome disorder, with a prevalence of 1 in 500 males. Signs of KS include low testosterone levels (63-85\%), increased prepubertal and adult height $(30 \%)$, reduced muscle mass, decreased facial hair (60-80\%), and decreased pubic hair (30-60\%) [8]. KS is strongly associated with male hypogonadism (95\%) and infertility (91-99\%) [9].

The syndrome is highly underdiagnosed. Only $10 \%$ of cases are diagnosed prepubertally and $<25 \%$ of adult male patients are diagnosed. This can be attributed to the fact that the KS phenotype varies and there are no definitive clinical criteria that define the syndrome [8].

Hair distribution in KS is scarcely described in the literature. Barr [2] described delayed and sparse facial hair (average 18-20 years) and gynecoid distribution of pubic hair in KS. Groth et al. [7] documented decreased facial hair in $60-80 \%$ of cases and diminished pubic hair in 30 $60 \%$ of cases. 
KS does not protect the affected male from having AGA [2]. Baldness was reported in 19\% (20 out of 104) patients of KS with a mean age of 45 in a large study [10]. Braun-Falco and Milbradt [11], described a 40 years old male patient with KS who had diffuse alopecia. The hair was thin in caliber, with normal pigment and trichogram showed predominantly telogen root (over $40 \%$ in the fronto-occipital scalp) [11].

KS can be associated with rare cutaneous syndromes usually lethal in male newborns. Testing for KS is always recommended in males with features of X-linked genodermatoses such as incontinentia pigmenti and focal dermal hypoplasia [12-16]. Other non-syndromic cutaneous manifestations and associations that have been reported in KS including varicose veins, leg ulcers and connective tissue diseases (Table 1).

AGA is caused by androgen-dependent miniaturization of scalp hair follicles. Scalp DHT is implicated as a contributing cause. Finasteride, an inhibitor of type II 5 alpha-reductase, is approved by Food and Drug Administration (FDA) for treatment of AGA in men [17]. A double-blind, randomized, placebo-controlled trial showed that finasteride decreases both scalp and serum DHT levels by $>60$ and $70 \%$ respectively. Scalp testosterone level was significantly increased (40\%) and serum testosterone level was variably increased (12.5\%) [18-20].

Increased testosterone levels can increase estrogen levels through peripheral aromatization. The estradiol levels increased by $10-15 \%$, but remained within physiological normal ranges, with no evidence of alteration of the hypothalamic pituitary testicular regulatory axis, no significant reduction in prolactin, luteinizing hormone or follicle stimulating hormone as compared with placebo [21].
The serum testosterone elevation during finasteride treatment might be beneficial in the management of patients with KS with AGA due to the fact that testosterone supplementation is a treatment of KS.

In conclusion, patients with KS can develop AGA and finasteride is a good treatment option for these patients who might also benefit from the increase level of serum testosterone during finasteride treatment.

\section{Statement of Ethics}

Subject guardians have given their informed consent to publish details of the case.

\section{Conflict of Interest Statement}

Dr. Alsalhi has no conflict of interest. Dr. Tosti declares that she has the following conflicts of interest: consultant/advisory board for P\&G, DS Laboratories, Monat, Thirty Madison, Almirall, and Lilly.

\section{Funding Sources}

The authors did not receive any funding.

\section{Author Contributions}

Article conception and design: A. Tosti and W. Alsalhi. Acquisition of data: A. Tosti and W. Alsalhi. Analysis and interpretation: A. Tosti and W. Alsalhi. Preparation of the outline of the manuscript: A. Tosti and W. Alsalhi. Literature review: A. Tosti and W. Alsalhi. Critical review and supervision: A. Tosti and W. Alsalhi.

\section{References}

1 Klinefelter HF, Reifenstein EC, Albright F. Syndrome characterized by gynecomastia, aspermatogenesis without A-leydigism, and increased excretion of follicle-stimulating hormone. J Clin Endocrinol Metabol. 1942 Nov;2(11):615-27.

2 Barr ML. The natural history of Klinefelter's syndrome. Fertil Steril. 1966;17(4):429-41.

3 Hamilton JB. Male hormone stimulation is a prerequisite and incitant in common baldness. J Invest Dermatol. 1942;5(6):473-4.

4 Williams GR, Franklyn JA. Physiology of the steroid-thyroid hormone nuclear receptor superfamily. Baillieres Clin Endocrinol Metab. 1994;8(2):241-66.

5 Patterson MN, McPhaul MJ, Hughes IA. Androgen insensitivity syndrome. Baillieres Clin Endocrinol Metab. 1994 Apr;8(2):379-404.
6 Cousen P, Messenger A. Female pattern hair loss in complete androgen insensitivity syndrome. Br J Dermatol. 2010;162(5):1135.

7 Groth KA, Skakkebæk A, Høst C, Gravholt $\mathrm{CH}$, Bojesen A. Clinical review: Klinefelter syndrome: a clinical update. J Clin Endocrinol Metab. 2013;98(1):20-30.

8 Futterweit W, Dunaif A, Yeh HC, Kingsley P. The prevalence of hyperandrogenism in 109 consecutive female patients with diffuse alopecia. J Am Acad Dermatol. 1988;19(5 Pt 1): 831-6.

9 Visootsak J, Graham JM. Klinefelter syndrome and other sex chromosomal aneuploidies. Orphanet J Rare Dis. 2006;1(1):42-5.

10 Becker KL. Clinical and therapeutic experiences with Klinefelter's syndrome. Fertil Steril. 1972;23(8):568-78.
11 Braun-Falco O, Milbradt R. [Chronic diffuse alopecia of the pseudo androgenetic type in Klinefelter's syndrome]. Hautarzt. 1971 Aug; 22(8):358-9.

12 Kucinskiene V, Strazdiene D, Valiukeviciene $S$. Incontinentia pigmenti in a male infant with Klinefelter syndrome: a case report and review of the literature. Pediatr Dermatol. 2010;27(5):492-5.

13 Burkhardt D, Schuffenhauer S, Peter RU, Walther JU, Ruzicka T. [Incontinentia pigmenti in a male patient]. Hautarzt. 1993 Mar; 44(3):153-6.

14 Arbor A. Incontinentia pigmenti in a male infant with Klinefelter syndrome. J Am Acad Dermatol. 1989:(5 Pt 2):937-40.
Androgenetic Alopecia in Klinefelter Syndrome
Skin Appendage Disord 2021;7:135-138 DOI: $10.1159 / 000512224$ 
15 Alkindi S, Battin M, Aftimos S, Purvis D. Focal dermal hypoplasia due to a novel mutation in a boy with klinefelter syndrome. Pediatr Dermatol. 2013;30(4):476-9.

16 Skaria A, Feldmann R, Hauser C. [The clinical spectrum of focal dermal hypoplasia]. Hautarzt. 1995 Nov;46(11):779-84.

17 Libecco JF, Bergfeld WF. Finasteride in the treatment of alopecia. Expert Opin Pharmacother. 2004;5(4):933-40.

18 Drake L, Hordinsky M, Fiedler V, Swinehart J, Unger WP, Cotterill PC, et al. The effects of finasteride on scalp skin and serum androgen levels in men with androgenetic alopecia. J Am Acad Dermatol. 1999 Oct;41(4):550-4.

19 Randhawa HK, Hamilton J, Pope E. Finasteride for the treatment of hidradenitis suppurativa in children and adolescents. JAMA Dermatol. 2013;149(6):732-5.

20 Cranwell WC, Sinclair R. Loose anagen hair syndrome: treatment with systemic minoxidil characterized by marked hair color change. Aust J Dermatol. 2018;59(4):e286-7.
21 PROPECIA $^{\bullet}$ (finasteride) [package insert]. Whitehouse station, NJ: Merck Sharp \& Dohme Corp.; 2014.

22 Lanfranco F, Kamischke A, Zitzmann M, Nieschlag E. Klinefelter's syndrome. Lancet. 2004 Jul;364(9430):273-83.

23 Krause WKH. Skin diseases in Klinefelter syndrome. Austin Androl. 2017;2(1):1013.

24 Harris VM, Sharma R, Cavett J, Kurien BT, Liu K, Koelsch KA, et al. Klinefelter's syndrome $(47, \mathrm{XXY})$ is in excess among men with Sjögren's syndrome. J Clin Immunol. 2016; 168:25-9.

25 Gattringer C, Scheurecker C, Höpfl R, Müller $\mathrm{H}$. Association between venous leg ulcers and sex chromosome anomalies in men. Acta Derm Venereol. 2010 Nov;90(6):612-5.

26 Ashwini JM. Klinefelters syndrome with a cutaneous manifestation of lower limb ulceration. J Clin Exp Dermatol Res. 2015;6(3):12.
27 Yabuno Y, Tosa M, Iwakiri I, Nomoto S, Kaneko M, Kuwahara K, et al. Refractory leg ulcers associated with Klinefelter syndrome. J Nippon Med Sch. 2015;82(1):64-7.

28 Dillon S, Aggarwal R, Harding JW, Li LJ, Weissman MH, Li S, et al. Klinefelter's syndrome (47,XXY) among men with systemic lupus erythematosus. Int J Pediatr Adolesc. 2011;100(6):819-23.

29 Kobayashi S, Shimamoto T, Taniguchi O, Hashimoto H, Hirose S. Klinefelter's syndrome associated with progressive systemic sclerosis: report of a case and review of the literature. Clin Rheumatol. 1991;10(1):84-6.

30 Nieschlag E. Klinefelter syndrome: the commonest form of hypogonadism, but often overlooked or untreated. Dtsch Arztebl Int. 2013;110(20):347-53.

31 Moshakis V, Fordyce MJ, Griffiths JD. Klinefelter's syndrome associated with breast carcinoma and Paget's disease of the nipple. Clin Oncol. 1983 Sep;9(3):257-61. 